FERMILAB-TM-1722

\title{
Education Programs at the DOE National Laboratories: Benefits to Teachers and Students*
}

\author{
Marjorie G. Bardeen \\ Fermi National Accelerator Laboratory \\ P.O. Box 500 \\ Batavia, Illinois 60510
}

March 1991

* Presented at the Third Annual International Industrial Symposium on the Super Collider [ITSSC], Atlanta, Georgia, March 13-15, 1991. 
EDUCATION PROGRAMS AT THE DOE NATIONAL LABORATORIES:

\title{
BENEFITS TO TEACHERS AND STUDENTS
}

\author{
Marjorie G. Bardeen \\ Education Office, \\ Fermi National Accelerator Laboratory \\ Batavia, IL
}

\begin{abstract}
In 1980, when Fermilab began supporting precollege education programs, it was not at all clear that a research laboratory was an appropriate setting for major precollege education programs. Participants have given us the answer, "Yes!" Programs for students and teachers work at national laboratories because it is not business as usual. Participants come to a world class research laboratory for a unique opportunity to witness science conducted at the frontier of human understanding. They gain invaluable experience being in an environment where science is done. We have shown that teachers, in particular, respond positively to being treated as professionals and peers by researchers. Benefits to teachers and students from participating in a national laboratory's education programs may be broadly categorized as either changed attitudes toward science or new knowledge about science and science teaching and will be described.
\end{abstract}

\section{INTRODUCTION}

Department of Energy (DOE) national laboratories and other facilities have the resources to give students and teachers a unique experience in the world of science, an experience that will stimulate the intellectual curiosity of the students and enhance the instructional abilities of their teachers. The culture of the science classroom is a far cry from the culture of the research science laboratory. In school it is important to get the correct answer; in the laboratory it is important to ask a good question. In school it's all in the book; in the laboratory the book is being written. In school the teacher knows the answer, in the laboratory even the director cannot be certain of the research results.

Students need to broaden and enrich their attitudes toward and develop their appreciation for science. Students need to be exposed to content in line with current scientific knowledge. For example, quarks, photons, gluons and W's, the Big Bang, the SSC are high energy physics topics that form an exciting frontier in modern science, one that holds the potential of capturing the interest of young students and creating young scientists. Yet, few of our students have any exposure to today's science before they have dropped out of the pipeline. 
Students need teachers who are enthusiastic and excited about and deeply involved in the teaching they do. Many precollege teachers, particularly elementary school teachers, lack a strong academic background in science or mathematics. Teachers who are uncomfortable or unfamiliar with science teach by the book, and their students memorize seemingly unrelated facts, rules and formulas. Their students need to spend more time investigating the world around them. At the junior high and high school level, science teachers tend to be isolated from new developments in their disciplines within a few years after they leave college and enter the classroom. They have few opportunities for keeping current in their fields or for developing the kind of collegial relationships with research scientists that could help to enhance the status of the teaching profession.

Sustained efforts are required to give students an opportunity to experience the world of science first hand. Sustained efforts are required to give teachers both a more solid and up-to-date background in their subject and better teaching strategies and tools. While DOE alone cannot expect to influence the entire national precollege education system, DOE can help by working closely with industry, other federal agencies, state and local governments, and the education community to improve the system with steady and reliable support.

The benefits to teachers and students who participate in DOE precollege education programs accrue because the participants are exposed to or in some cases immersed in the culture of science as typifyed by a national research laboratory. Those benefits may be broadly categorized as either changed attitudes toward science or new knowledge about science.

\section{BENEFITS - CHANGED ATTITUDES}

High School Student, "...Saturday Morning Physics is a wonderful idea. It gives students that extra boost of motivation and confidence..."

Much of science is taught as a 'dead' subject. While it is important for students to understand basic scientific principles that were discovered long ago, it is equally important and stimulating for them to be familiar with current topics, particularly those covered in the popular press. A visit to a national laboratory, whether for half a day or for two weeks, shows that science is alive and develops a special vitality and excitement in students. The research scientists share that same vitality and excitement, and it shows when they meet the students.

For students the common image of science is that of the "Mad Scientist." Programs that bring students to national laboratories or bring laboratory scientists to schools change the students' perceptions of science. At Fermilab, for example, they see a beautiful building that looks neither industrial nor military. They learn that men and women physicists work at Fermilab. These researchers are real people; they ride bikes, wear levis and have a sense of humor. Students learn that Fermilab scientists are interested in more than physics; for example, in the environment as demonstrated by a vigorous recycling program, a prairie restoration project, and maintenance of a buffalo herd; in art and music as demonstrated not only by the Laboratory architecture but also by the art on display and the public concerts and dance series offered in the Laboratory auditorium.

High School Teacher, "Do you recall the Toyota commercial ... where the people yelled 'Oh, What a Feeling!...,' as they jumped three feet into the air? That fairly well describes my feelings about my experience of the past month at the Summer Institute for Science Teachers at Fermilab. I am actually anticipating my return to school this fall where I can try out some of my newly 
acquired knowledge on my unsuspecting students."

Teachers have a renewed sense of pride in their profession when they spend time at a national laboratory. Many realize, perhaps for the first time, that real scientists admire the job they do and respect their work. They get a real boost in status at school, in the education community and in their hometown. If we expect teachers to stay in the classroom, if we expect to encourage students to become teachers, we must continue to support teachers by making them feel a part of the larger scientific enterprise.

An important strategy we have adopted at Fermilab gives teachers leadership roles in our precollege education programs as seen by both their peers and research scientists. Teachers participate in needs assessment workshops, serve on program development committees and work as project directors and coordinators and instructors in all of our programs. This helps establish continuing communication channels between researchers and teachers and develops the feeling of community.

High School Teacher, "Excitement has been infused into fifteen classrooms and into hundreds of young people studying physics for the first time. These students are getting an exceptional education, after all, they would tell you...'My teacher spent the summer at Fermilab!"'

\section{BENEFITS - NEW KNOWLEDGE}

High School Student, "The lectures alone made me decide to go into physics. The lectures gave me a much better perspective of what physics is all about than one could ever get from a high school physics class."

Programs for students stimulate their intellectual curiosity when we present material beyond the textbook in the context of real science. Whether the student is the elementary school student experimenting with the effects of gravity, the middle school student learning how physicists study things they can't see or the high school student beginning to grasp the meaning of the Standard Model, their newly gained knowledge can stimulate a deeper interest in science.

High School Teacher, "Before I came to the Institute, I felt I knew most of the answers. As time progressed, I realized just how much had transpired since I was last a student, and at times I didn't even understand the questions. This has been a richly rewarding and stimulating experience for me..."

In DOE research participation programs or in summer institutes at DOE facilities teachers gain new knowledge in three main areas - scientific developments, teaching strategies and instructional materials. Exciting science classes demonstrate sound scientific principles based on analytical thinking, present content in line with current scientific and mathematical knowledge, and teach problem solving and applications using computer technology.

At DOE laboratories we expose teachers to current developments in scientific research and basic objectives and problems in modern science. At the same time we are able to enhance teachers' backgrounds in basic subject matter currently taught in schools. We strengthen the awareness and teaching of contemporary relations among science, mathematics, technology and society.

By providing teachers with a hands-on research experience, we can lead teachers to offer their students a hands-on education "starting with questions about phenomena rather than with answers to be learned; engaging students actively in the use of 
hypotheses, the collection and use of evidence, and the design of investigations and processes; providing students with hands-on experience with mechanical, electronic and optical tools; placing a premium on students' curiosity and creativity; and frequently using a student team approach to learning." 1 In our institutes and workshops staff teachers identify and demonstrate successful and lively teaching techniques including laboratory preparation and techniques and computer and graphing calculator applications.

High School Teacher, "My students have noticed my interjections of the work at Fermilab as they now come to me more often asking about Superconductors, Super Colliders, quarks, etc. They enjoy being able to find these topics in the news, whether they read them or hear them."

\section{CONCLUSION}

We cannot expect the schools to raise the literacy of the nation all alone. Many outside partners can and must contribute. We can double and triple our efforts by creating innovative partnerships between the education community and national laboratories and business and industry, between informal and formal science programs. National laboratories can turn on students and teachers to science.

The strength of the DOE precollege education programs lies in the DOE laboratories, their staffs and their facilities. When Fermilab began in 1983, it was not at all clear that a research facility was an appropriate setting for major teacher inservice programs. Teachers and students have given us the answer. "Yes!" Precollege education programs work at Fermilab because it is not business as usual. Teachers come to a world class high energy physics research laboratory for a unique opportunity to witness science conducted at the frontiers of human understanding. Teachers gain invaluable experience learning from leading research scientists. Students have an experience in science that broadens and enriches their attitudes and develops their appreciation for science. Students see, perhaps for the first time, what the world of science is really like, and they like what they see!

1. Project 2061 Science for All Americans Summary, American Association for the Advancement of Science, Washington, D.C. 1989, p. 11. 